Etnográfica

Revista do Centro em Rede de Investigação em

Antropologia

vol. $16(2) \mid 2012$

Vol. $16(2)$

\title{
Quando lembrar é amar: tempo, espaço, memória e saudade nos ritos fúnebres católicos
}

When to remember means to love: time, space, memory and saudade in the catholic funeral rituals

\section{Mísia Lins Reesink}

\section{(2) OpenEdition}

\section{Journals}

Edição electrónica

URL: https://journals.openedition.org/etnografica/1535

DOI: 10.4000/etnografica.1535

ISSN: 2182-2891

\section{Editora}

Centro em Rede de Investigação em Antropologia

\section{Edição impressa}

Data de publição: 1 junho 2012

Paginação: 365-386

ISSN: 0873-6561

\section{Refêrencia eletrónica}

Mísia Lins Reesink, «Quando lembrar é amar: tempo, espaço, memória e saudade nos ritos fúnebres católicos», Etnográfica [Online], vol. 16 (2) | 2012, posto online no dia 26 junho 2012, consultado o 10 fevereiro 2022. URL: http://journals.openedition.org/etnografica/1535 ; DOI: https://doi.org/10.4000/ etnografica. 1535

\section{(c) (i) (8)}

Etnográfica is licensed under a Creative Commons Attribution-NonCommercial 4.0 International License. 


\section{Quando lembrar é amar: tempo, espaço, memória e saudade nos ritos fúnebres católicos}

\section{Mísia Lins Reesink}

A morte e o "complexo ritual fúnebre católico" são eventos que abrem espaço para a reflexão etnográfica sobre possíveis relações entre a morte (em especial sua dimensão ritual), o tempo, o espaço, a memória e a saudade. Este texto pretende assim explorar essas possibilidades, a partir dos eventos de mortes nas vidas de sujeitos católicos do bairro de Casa Amarela, Recife (Brasil); nesse sentido, parece ser possível estabelecer uma relação estrutural-temporal em que se percebe a construção de diferentes tempos/tipos de memórias, cujas bases são, de um lado, a dimensão afetiva (sobretudo, a saudade) e, de outro, a ritual (como o ritual de Finados), na produção do "ente querido".

PALAVRAS-CHAVE: memória, saudade, morte, católicos, tempo-espaço, Recife.

When to remember means to love: time, space, memory and saudade in the catholic funeral rituals - Death and the "catholic funeral ritual complex" are events that may inspire ethnographic reflections about the relations between death (particularly its ritual dimension), time, space, memory and saudade. Here I want to explore some of these possibilities by looking at the events occurring after the death of catholic people in the Casa Amarela neighbourhood of Recife (Brazil). It seems to be possible to establish a structural-temporal relationship between these dimensions and hence to construct different times/types of memories based upon, on the one hand, an affective dimension (particularly saudade), and, on the other, a ritual dimension (as in the Day of the Dead), in the production of the "beloved being".

KEYWORDS: memory, saudade, death, catholics, time-space, Recife.

REESINK, Mísia Lins (emreesink@gmail.com) - Universidade Federal de Pernambuco, Brasil 


\section{NÃO SEI SE DEVERIA CONSIDERAR ESTA REFLEXÃO COMO UMA} contribuição a uma antropologia do amor (ou da afetividade), a uma antropologia da morte, da religião ou da memória. Talvez seja tudo isso ao mesmo tempo, pois a morte parece ser um desses fenômenos que nos faz retornar à companhia segura dos clássicos para afirmar que se trata de um "fato social total". Todavia, ao se falar de fenômeno social total se está falando ao mesmo tempo dessa incapacidade inerente à totalidade de ser apreendida "totalmente", o que nos leva a "desconstruir" analiticamente o fenômeno, na tentativa de reconstruir uma pseudototalidade (que traduzimos como "recortes ou dimensões"), cujo principal efeito é um reconforto emocional, no sentido em que nos parece tornar possível compreender a realidade da qual falamos, ao mesmo tempo em que poderia nos possibilitar ser compreendidos pelos outros. ${ }^{1} \mathrm{O}$ fenômeno da morte é, consequentemente, aqui discutido como fato social total não "totalizável", partindo das elaborações rituais que católicos de Casa Amarela, bairro do Recife (Pernambuco, Brasil) realizam em relação ao evento da morte, e articulando a partir dessa dimensão ritual o tempo, o espaço, a memória e a saudade, em que parte do que está em jogo é a produção do morto como "ente querido".

O fio que conduz, portanto, a argumentação do texto é a ideia de que a elaboração de diferentes tempos/tipos de memórias, articulados aos afetos (saudade) e rituais, em processos de interconexões com o tempo e o espaço, é condição para a produção de uma categoria de "pessoa" fundamental na cosmologia católica brasileira: o ente querido; este implica relações (de parentesco ou de afinidade) entre os vivos, entre os vivos e os mortos e, sobretudo, a preocupação com o destino das almas dos mortos que estão em algum tipo de relação com os vivos. Menos do que apresentar uma teoria da memória, da saudade ou dos rituais, este artigo pretende refletir, a partir de dados etnográficos, exatamente aquilo que me parece ausente da literatura antropológica sobre o contexto do catolicismo brasileiro (e quiçá de outros): as interconexões entre estes elementos (memória, saudade, tempo, espaço, ritos), que parecem ser intrínsecas e vitais à (re)produção e continuidades dos afetos e das relações entre vivos e mortos, podendo o todo ser compreendido como um complexo cognitivo/afetivo.

Com vistas a isto, primeiramente apresentarei brevemente o campo etnográfico e o que denomino de "complexo ritual fúnebre católico"; logo depois, avançarei uma reflexão sobre a memória (e seus tempos/tipos) como condição na produção do ente querido, articulando esta análise com a compreensão da saudade como categoria do "coração"; finalmente, a partir das noções de

1 Uma primeira versão deste trabalho foi apresentada na 27. ${ }^{\mathrm{a}} \mathrm{RBA}$, em Belém-PA, Brasil, 2010. Agradeço ainda os comentários de E. Reesink, R. Campos e dos pareceristas anônimos. Esse trabalho não seria possível sem os financiamentos concedidos para o desenvolvimento das pesquisas de campo, em diferentes momentos, pela Capes, CNPq e Fapesb. 
tempo e espaço, e tomando a morte de um indivíduo como evento, discutirei as possíveis interconexões entre tempo, espaço, memória e saudade na produção do ente querido; encerro, a seguir, com as minhas considerações finais.

\section{CATÓlICOS DO BAIRRO E O “COMPLEXO RITUAL FÚNEBRE CATÓLICO”}

Casa Amarela é um dos bairros mais interessantes da cidade do Recife, tanto pela sua história (de lutas pela posse de terra - que contaram com a colaboração importante da ala progressista da Igreja Católica), quanto pelo fato de se tratar de um bairro de grandes dimensões e bastante populoso, dividido em áreas de morro, onde ficam prioritariamente os habitantes das camadas populares, e uma área plana, onde habitam os moradores das camadas médias (Reesink 2003). ${ }^{2}$ Além disso, tem um dos santuários religiosos mais populares da cidade, o Morro da Conceição, dedicado a Nossa Senhora da Conceição, padroeira do bairro. Casa Amarela possui ainda considerável autonomia econômica e de infraestrutura, com um comércio próprio, incluindo um mercado público e feira livre, hospital público e, particularmente, um cemitério que atende prioritariamente os habitantes do bairro, havendo ainda diversas casas funerárias.

Das relações estabelecidas em campo, a composição do meu grupo prioritário de informantes foi de 60 sujeitos: $^{3}$ são adultos, com mais de 19 anos, cujo grau de escolaridade varia de analfabetos a graduados; entre eles há desempregados, donas de casa, profissionais liberais, pequenos comerciantes, funcionários públicos e de empresas privadas, estudantes, aposentados. Como não havia um interesse específico em fazer um recorte de gênero, o próprio campo determinou uma maior quantidade de mulheres, tendo em vista a minha condição de gênero e a maior permanência delas em casa. Os meus interlocutores católicos que moram no bairro compõem o que chamo de "católicos cotidianos", no sentido de que são sujeitos que se autodenominam católicos, mas que não fazem parte, necessariamente, de um "tipo" católico específico ou atraente, vis-à-vis um suposto exotismo (como, por exemplo, os carismáticos ou os peregrinos).

O meu ponto de interesse, assim, tem se centrado na "movimentação" dos católicos do bairro, e é em relação a esse espaço que eles foram (e são) particularmente considerados. Esses católicos costumam estabelecer diferenças entre

2 Desde 1994 até o presente, venho realizando diferentes pesquisas nesse bairro, em especial procurando compreender a cosmologia católica, conjugada às representações e aos rituais de morte. O texto aqui elaborado é o resultado de um repensar sobre os dados obtidos ao longo desse período.

3 A maneira como entrei em contato com esses informantes foi, prioritariamente, pelo método da rede de relações, mas também através de um questionário (exploratório) aplicado nas duas áreas do bairro onde realizo pesquisas (na comunidade do Alto do Reservatório - área de morro; e na parte "nobre"), em que eram solicitados contatos posteriores. 
si, não a partir do ponto de vista de serem católicos verdadeiros ou católicos nominais (classificação comum entre os cientistas sociais brasileiros), pois o batismo é o definidor primeiro da pertença católica, mas sim a partir da intensidade da prática ritual. Dessa forma, diante de uma variedade enorme de ritos católicos (missas, rezas, terços, novenas, peregrinações, procissões, etc.), e da maior ou menor intensidade da sua prática realizada pelos meus informantes, é possível elaborar um modelo do conjunto de ritos performados por esses católicos nos eventos de morte, que designo de "complexo ritual fúnebre católico", compreendendo este tanto "ritos de passagem", quanto de "oblação", seguindo os termos propostos por Thomas (1975, 1985) e Van Gennep (1969 [1909]).

Ao que tudo indica, os seres humanos, diante da morte, elaboram por toda parte ritos de oblação (acompanhamento do moribundo, retenção do corpo), de separação e de integração, como definido por Thomas, adaptando o modelo de Van Gennep. Este consagrou o conceito de ritos de passagem, em que a morte possui um lugar de destaque: neste sentido, há os ritos de separação, os ritos de margem e os ritos de agregação do morto ao mundo dos mortos e dos vivos ao mundo dos vivos. ${ }^{4}$ Apesar de o termo oblação não dar conta de toda a evolução ritual que essa etapa encontra entre os católicos de Casa Amarela, parece ser razoável mantê-lo para a distinguir dos outros momentos rituais contidos na noção de ritos de passagem, pois, nesse contexto, há certamente ritos de oblação seguidos de ritos de passagem, na elaboração do processo ritual fúnebre.

Nesse sentido, e esquematicamente, pode-se dizer que, no contexto do "complexo ritual fúnebre católico", as etapas dos ritos de passagem fúnebres, além dos ritos de oblação, compreendem os momentos da morte, incluindo os cuidados com o cadáver; do velório e do enterro; e o do luto, que envolve os rituais das missas (de sétimo dia, de mês, de ano), as rezas e velas (cotidianas ou não) pelas almas dos mortos e o período de Finados. ${ }^{5}$ As velas e rezas são símbolos e objetos fundamentais na economia da salvação das almas no catolicismo, presentes, de maneira separada ou conjugada, em todas as etapas do complexo ritual fúnebre católico (Reesink 2010).

Importa sublinhar, entretanto, que quando falo desses ritos de passagem levo em conta que eles não são elaborados apenas a partir de uma única posição de referência, mas de várias, que se superpõem, podendo englobar aquilo que se denomina de ritos de oblação. Como já sinalizou Danforth (1982), no que tange o fenômeno da morte, existem inúmeras modalidades de separação

4 Até onde conheço, a literatura etnográfica e etnológica sobre os rituais fúnebres em diferentes contextos culturais concorda com a generalidade da estrutura processual proposta por Van Gennep, em que a diversidade ritual é analiticamente classificada nesta estrutura processual. Sublinho que a tomo aqui como modelo heurístico.

5 Para uma discussão e descrição aprofundada do "complexo ritual fúnebre católico" em Recife, ver Reesink (2003). 
e de agregação, e, portanto, variadas situações de margem. No contexto dos católicos de Casa Amarela, é possível assinalar algumas recomposições dessa estrutura processual, segundo a posição que se ocupe. Assim, quanto ao processo da morte, há a separação do morrente do mundo dos vivos, seu estatuto transitório de moribundo (nem morto, nem vivo) e enfim sua integração no estatuto de morto; o que implica em dizer que os ritos de oblação, agora, seriam transformados em ritos do período liminar.

Em relação às almas, para a maioria delas, o trio céu-purgatório-inferno dá conta dos termos de separação-margem-agregação: separação do corpo, transição purificadora no lugar intermediário, integração no mundo dos salvos. Do ponto de vista do sobrevivente, há, primeiro, separação engendrada pela morte de outro vivo, o período liminar do velório e a integração do corpo ao seu destino - a tumba, através dos ritos de enterramento. Olhando a partir de outro ponto de referência, ainda quanto ao sobrevivente: há a vida cotidiana, a passagem para o período de transição do luto, a reintegração do indivíduo transformado pelo fim do luto; em relação ao corpo: há o corpo vivo, o corpo morto sobre a terra, o corpo morto integrado à terra. Assim, quando se fala de morte, como dito, isto compreende habitualmente várias (re)composições das etapas rituais, sendo evidente que a maior parte dessas etapas não provoca necessariamente elaborações rituais complexas ou mesmo imediatamente percebidas como sendo gestos rituais.

Se essas breves considerações descrevem possíveis combinações das estruturas rituais (e seus conteúdos) diante do evento da morte, elas não mencionam, contudo, a sua dimensão emocional. Muito já se escreveu sobre isto, mesmo porque a morte é um evento privilegiado para observar a expressão emocional dos diferentes povos. ${ }^{6}$ De qualquer forma, parece-me, de uma maneira geral, que as reflexões antropológicas elaboradas em torno dos rituais fúnebres tendem a pôr mais ênfase nos conteúdos estruturais ou processuais desses ritos, deixando pouca margem à combinação desses elementos com as suas dimensões emocional, afetiva e de memória.

Minha pretensão aqui, nesse sentido, é a de inverter a ênfase e de centrar a reflexão nestes últimos aspectos, sublinhando exatamente as questões relacionadas às emoções (que compreendem sentimentos e afetividades). Estas são costumeiramente estudadas dentro das discussões desenvolvidas pela "antropologia das emoções", que se funda sobre duas correntes principais: uma biologista e a outra culturalista (e suas derivações: cognitivista, construtivista, interpretativista). ${ }^{7}$ Para o fenômeno aqui discutido, acho interessante a posição

6 Porém, ao que parece, não é fácil para o pesquisador tudo contemplar ou mesmo a todos contentar. Ver, sobre isso, o debate entre Bloch e Parry (1982), Metcalf e Huntington (1991), e Rosaldo (1993).

7 Reenvio aqui aos comentários críticos - que historicizam e contextualizam essas correntes e seus debates - realizados por Leavitt (1996) e Costa (2002). 
de Leavitt (1996), que, em uma tentativa de superar a questão "biológica" ou "cognitiva" das emoções, avança que essas são ao mesmo tempo sentidas e pensadas, biológicas e culturais (feeling and meaning). A emoção seria, assim, "um sentimento associado a um significado" (Leavitt 1996: 515). ${ }^{8}$ Ele afirma, sobretudo, que para compreendê-las, "dever-se-ia reconhecer na teoria o que se assume na nossa vida cotidiana: as emoções são sentidas dentro de uma experiência corporal, não são apenas conhecidas ou pensadas ou apreciadas" (1996: 526).

É partindo desse pressuposto que o sofrimento provocado nos sobreviventes pelo evento da morte, e que é primeiramente identificado como a dor da perda, é aqui considerado, levando ainda em conta que o sofrimento é uma experiência social (Kleinman, Das e Lock 1997) e, como aponta Campos, pode ser performado, pois "nós aprendemos a sentir apropriadamente e entendemos o que sentimos através do reconhecimento de situações particulares. Isto porque as emoções não são meros estados íntimos, mas envolvem objetos externos" (Campos 2002: 256). Nesse sentido, nos eventos de morte, a dor da perda é socialmente/ritualmente performada e significada, ao mesmo tempo em que é vivida como íntima e particular. Mas, para além disso, é necessário ter em mente que, também nos eventos de morte, "o lugar social do sujeito qualifica a sua dor e determina a reação do outro em face da sua dor" (Sarti 2001: 10). Nesse contexto particular, esse lugar social do sujeito que sofre é aí demarcado, prioritariamente, pelas relações afetivas constituídas através das relações de parentesco ou de afinidades eletivas, componentes fundamentais na produção dos entes queridos.

\section{A MEMÓRIA E A PRODUÇÃO DO ENTE QUERIDO}

O que pretendo referir com "produção do ente querido" é exatamente o processo em que, com a morte de algum parente (sempre) ou de algum amigo amado (possivelmente), o morto é transformado em ente querido, termo nativo empregado comumente quando o informante faz referência aos "seus mortos", estes definidos, como já dito, pelas relações de parentesco e/ou de afinidades eletivas. Evidentemente, nesse processo de produção do ente querido, as trajetórias e características individuais dos sujeitos (idade, gênero, tipo e intensidade da afetividade para com o morto, etc.) têm impactos diversos; entretanto, numa abordagem menos "psicológica" e mais "socioantropológica", percebe-se que as distinções principais nesse processo se encontram, sobretudo, no fato de se ter ou não vivido a morte de um parente ou amigo, e se este é ou não um evento recente. Pode-se avançar, então, que o uso do termo "ente querido" expressa relações de afetividade (sobretudo de amor) entre vivos e mortos, em

8 Todos os textos aqui citados cujas edições consultadas estão em outra língua foram por mim traduzidos para o português. 
que a memória desempenha um papel fundamental na reprodução de uma afetividade positiva, ou mesmo no esforço de transformação dos sentimentos negativos em positividade. ${ }^{9}$

Em se tratando de memória, sem dúvida os trabalhos de Halbwachs (1994 [1925], 1997 [1950]) são marcos para os estudos das ciências sociais e, desde então, inúmeras páginas foram escritas sobre isso. Por isso não me proponho aqui a inovar neste tema, antes procuro me aproveitar das ideias de outros autores para tentar pensar a memória no processo da realização dos ritos fúnebres e na produção dos mortos como entes queridos. Nesse sentido, não é difícil perceber que o período e os lugares dos ritos de passagem - particularmente a etapa do luto - são tempo e espaço de memória (Reesink 2003). Esta se constitui sempre com e pela saudade, o que significa dizer que a memória é antes de tudo questão de afetividade, de amor, implicando evidentemente a obrigação e a "oblação".

No evento da morte de um ente querido, dois tipos de memória são, primeiramente, estabelecidos: perda e sofrimento. Antes, porém, quero sublinhar que há aqui uma aparente obviedade ao se relacionar a perda e o sofrimento com o evento da morte e da memória; entretanto, é justamente por se tratar de categorias nativas que essa aparente obviedade se revela com um potencial analítico importante na construção da minha reflexão sobre a produção do ente querido, ao serem aqui operadas como categorias analíticas, no sentido dado por Toren (2006). Assim, imediatamente após o falecimento, há a constatação do vazio, da saudade repentina que é sentida, sendo por esta razão que a memória-perda é instaurada; trata-se do desespero e da angústia provocadas pela rotura dolorosa; é a memória do "presente" ou, como diz Augé (1998), do "passado recente" que está em marcha, elaborada particularmente durante as exéquias. Quando da instauração da etapa do luto, a segunda memória se elabora, a memória-sofrimento, e é na missa de sétimo dia que encontramos o seu espaço e tempo privilegiado.

É interessante observar que a ideia de que a missa de sétimo dia é um lugar de memória e que tem uma ação terapêutica é uma concepção produzida tanto por uma "teoria nativa" dominante quanto por "teorias sociológicas". Dessa forma, o sociólogo italiano D’Agostino afirma que "o ritual da Igreja dá um sentido à morte pela ênfase posta na ressurreição do corpo e na salvação da alma" (D’Agostinho 1977: 19). Além disso,

“... no ritual do sacrifício há dois momentos de efeito terapêutico: a) a participação coletiva da comunidade age como um sacramento de solidariedade, de compensação e de partilha da dor; b) o valor simbólico

9 Em sentido geral, a afetividade é entendida aqui como compreendendo tanto sentimentos positivos (amor, carinho, etc.), quanto negativos (ódio, raiva, desprezo, etc.). 
do sacrifício em que a morte de Jesus Cristo é comemorada, refeita e incorporada pela comunhão. Nesse ritual, a presença de Maria, a Stabat Mater Dolorosa que perde um filho e permanece em face da cruz, ajuda na transformação do sofrimento, no alívio da angústia; é uma sublimação da morte, mas não é uma escapatória face a ela” (D’Agostinho 1977: 20).

Esta análise concorda com certa "teoria nativa” fornecida pelos meus informantes sobre o papel da missa no alívio do luto, pela afirmação e esperança na salvação, pelo exemplo de Cristo e da Virgem Maria. Eles estariam ainda mais inclinados a concordar com aquele raciocínio por ser aí valorizado o papel e a importância da comunidade na partilha do sofrimento.

"Do momento que completa os sete dias que a pessoa morreu... [...] Em relação a isso, a mensagem, eu acho que aquilo vai rever uma lembrança, o sétimo dia que ele já morreu, já se passou. Que passou a matéria, não é? Mas a alma não. Então aquilo ali está se relembrando muito em cima das pessoas, [sobretudo] das famílias que perderam aquela pessoa, está muito em cima, está relembrando muita coisa... E eu acho que é certo uma missa de sétimo dia" [D. Cícera, 51 anos].

"Eu nunca fui muito de missa [riso], mas eu acho que nesse sentido [a missa de sétimo dia do seu avô, a que ele não foi] não foi nem problema da missa, eu acho que foi realmente de lembrar, de estar lembrando. P'ra mim, como [era a] primeira vez [que] uma pessoa muito próxima, foi... mais forte. Mas hoje... eu iria. Acho que missa é importante, tem os seus defeitos, suas falhas, mas aí é uma questão pessoal minha, mas a gente deve... Essas missas de sétimo dia, não pelo morto que já está morto [riso], mas pelos outros parentes que também... Talvez a missa... É uma união p'ra acolher o todo e... É importante" [Marcos, 24 anos].

Disso resulta que, nessas interpretações, se a missa é uma ocasião e espaço de partilha da dor, para esses católicos, a missa é, sobretudo, momento de memória e de reforço dos laços familiares - em que o ente querido ocupa lugar de destaque. Nesse sentido, a família não fica "afastada" no que concerne o porquê desse momento: é nessa cerimônia que ela procura uma vez mais reorganizar sua própria estrutura, dar seguimento a ela mesma - é o tempo de "acolher o todo", como disse Marcos. A partir dessas interpretações e consciência nativas, a presença de todos é encorajada, para não dizer imposta. Se analisarmos cuidadosamente o que disse Marcos, poder-se-ia especular que a sua reflexão a posteriori da importância de se estar presente na missa de sétimo dia pode ter sido motivada tanto pela conclusão de ter vivido outra perda quanto pelas reclamações que seus pais lhe fizeram. 
De qualquer forma, se este informante quis se ausentar da missa de sétimo dia da morte de seu avô, é porque esse ritual implicava para ele outra ocasião de sofrimento. A missa de sétimo dia como lugar de produção de sofrimento não é o aspecto mais evidenciado pela maioria dos informantes, como visto, já que é, sobretudo, a sua dimensão terapêutica na solução desse sofrimento que é ressaltada. Contudo, e apesar disso, mesmo entre os informantes que tendem a minimizar o sofrimento nas suas narrativas desse ritual, é possível perceber a missa de sétimo dia como lugar (espaço) da memória-sofrimento.

“- E você acha, assim, que é importante a gente fazer missa de sétimo dia?

- É um sofrimento, mas é [importante].

- Porquê que é um sofrimento?

- Porque a gente relembra de muita coisa, a gente se desgasta mais, questão do ser humano, a gente... Quem fica.... Eu acredito que seja bem sofrido, bem difícil $[\ldots]$.

- E você acha que é mais difícil o momento de uma missa de sétimo dia ou o momento, assim, do enterro ou do velório?

- Olhe, são duas coisas distintas.

- Como assim?

- Porque o enterro é uma dor, realmente... P'ra mim, que eu já senti uma coisa tão..., que eu perdi, tão grande, tão grandiosa [...]. E na missa, a missa foi bem celebrada e ficou... Você a recordar, passo a passo de momentos alegres e momentos tristes, então ela deixa essa diferença assim" [André, 23 anos].

"Outra coisa que eu não faço questão é missa de sétimo dia, que eu acho que é você viver a morte da pessoa duas vezes, sabe? Acho até pior, porque os dias já têm passado e você já está melhorando, está entendendo? Daquele sentimento, daquela angústia. Aí, pô, tem uma missa de sétimo dia. Você encontra todo mundo ali, todos os amigos, todos os parentes, está entendendo? O padre vai falar, falar, falar do defunto, falar o nome do defunto [...]. A missa mexe muito com você [...]. Eu acho que a emoção é igual ou até maior do que no dia do enterro" [Fábia, 34 anos].

É porque se "ressofre" e na mesma intensidade que a missa do sétimo dia é tão dolorosa, pois ela mexe na ferida ainda aberta. É um momento tão impregnado de tristeza que, para Fábia, significa reviver passo a passo a mesma angústia das exéquias, numa negação da sua ação terapêutica.

Porém, para a maioria dos informantes, o sofrimento provocado pela missa é distinto do primeiro, pois trata-se de uma mistura de reconforto e dor. Desde então, são as lembranças que permanecem, são especialmente elas que são evocadas, as alegres e as tristes. Mas elas são derivadas da perda de um ente querido, nascem a partir da memória-perda, fonte alimentadora de sua vitalidade. 
Por isso, na missa, a memória que está em ação é a memória que faz sofrer, portanto, uma memória-sofrimento. Esta é tão potente que não deixa indiferentes os outros participantes do ritual, ainda mais quando se trata de uma missa individual, ou de um ofício em que o padre particulariza um morto.

Assim, igualmente constituída pela saudade, esta memória é sofrimento porque se "ressofre", ao se recordar, a experiência da perda. Apesar dessa consciência aguda do "ressofrer", para aqueles que realizam a missa de sétimo dia, esta se impõe como o compromisso do católico na contribuição para a salvação completa do ente querido no outro mundo: trata-se do cumprimento de um dever católico, mas é, sobretudo, percebido como uma prova de amor enviada pelos vivos aos mortos, mesmo que para isso seja preciso "submeter-se" à memória-sofrimento.

Esta memória-sofrimento representa, além disso, a relação entre memória, saudade e luto. Ao afirmar isso, pretendo pôr em evidência a dimensão afetiva da memória; ou seja, se, como sugere inúmeras vezes Halbwachs (1997 [1950]), a memória é seletiva, parece-me que essa seleção é sobretudo conduzida pela afeição, tanto positiva quanto negativa, quer dizer, pelo amor ou pelo ódio. Seria necessário, então, refletir um pouco mais sobre a capacidade das relações afetivas no processo, analisado por Pollak, "do esquecimento ou da transformação da memória" (1993: 23). Com isso, poder-se-ia melhor compreender a maneira como os indivíduos constroem a memória dos mortos e conservam suas relações com estes últimos, pois a manutenção disso depende e muito do processo de seleção, guiado pelo amor, que procura pôr em evidência só os bons momentos.

Como diz ainda Pollak, "existem, nas lembranças de uns e outros, zonas de sombras, de silêncios, de "não ditos" (1993: 27). Estes "não ditos" são as gavetas da memória, onde os indivíduos escondem os momentos interditos e dolorosos, aqueles que poderiam impedir ou estragar suas relações com os entes queridos. É, sem dúvida, por esta razão que Júlio, um rapaz de 22 anos, me disse francamente que só se deve lembrar os bons momentos. Deve-se dizer, contudo, que esses movimentos não são sempre realizados, tendo em vista que, "assim como as memórias coletivas e a ordem social que elas contribuem a constituir, a memória individual resulta da gestão de um equilíbrio precário, de uma multitude de contradições e de tensões" (Pollak 1993: 38). Mesmo assim, é pela construção dessas memórias, tanto individual quanto coletivas (ou familiares), que os vivos permanecem ligados aos mortos.

Outro ponto deve ser considerado mais de perto nesse processo: o trabalho do luto implica em esquecimento. É preciso esquecer para que o luto se faça. Disso decorre que

“... o esquecimento é necessário tanto à sociedade quanto ao indivíduo.

Tem-se que saber esquecer para saborear o presente, do instante e da espera, 
mas a própria memória precisa do esquecimento: tem-se que esquecer o passado recente para reencontrar o passado antigo" (Augé 1998: 7).

Assim, seria possível argumentar que, sem o esquecimento, o trabalho do luto seria impossível e a memória irrealizável, pois para se fazer a memória é necessário estar no presente, o que implica em dizer, estar na vida. ${ }^{10}$ Dessa forma, essa tensão entre memória e esquecimento se estabelece nos constrangimentos sociais, particularmente familiares, que produzem os interditos, tais como o de não "falar mal do morto", sobretudo na presença de não parentes: quando isso acontece, quando a narrativa que fala do ente querido, por meio dessa tensão, é quebrada pela introdução do "falar mal do morto", tornam-se quase palpáveis os silêncios reprovadores, os olhares constrangidos e constrangedores, as tentativas de silenciar a narrativa dissidente. ${ }^{11}$

Apesar do que foi dito acima, evocar o esquecimento pode conduzir a interpretações em que o esquecimento equivale ao não-amor. Esta apreciação engendra um paradoxo no esquecimento, paradoxo este que é sentido e percebido pelos próprios indivíduos.

"A própria vida se encarrega de nos confortar um pouco, de fazer a gente esquecer um pouco a pessoa, não é? [...] [Mas], eu acho que não tem como esquecer! Alguém que conviveu, que seja um parente, um amigo ou um vizinho, a gente não esquece. Eu não consigo esquecer as pessoas que eu amava e que estão mortas" [Raquel, 47 anos].

Mas, se é preciso o esquecimento para viver, e ele é imposto mesmo pela duração, ao mesmo tempo é impossível esquecer o ente querido, porque o “esquecimento não é falta de memória, não é não-memória, não é menos-memória” (Lins 2001: 51). De fato, esquecimento e memória são parceiros, tendo em vista que eles

“... mantêm de alguma maneira a mesma relação que a vida e a morte. A vida e a morte só se definem uma em relação à outra. [...] Esta proximidade das duas duplas - vida e morte, memória e esquecimento - é em todo lugar sentida, expressa e mesmo simbolizada" (Augé 1998: 20-21).

10 Aliás, é esta a consciência que possui a coletividade: quando ela afirma que é necessário esquecer, ela quer sinalizar com isso que é necessário viver o presente, especialmente quando do processo de realização do período de luto. Para uma discussão e descrição do luto entre católicos, ver Reesink (2003).

11 Em todos esses anos de experiência de campo em Casa Amarela presenciei apenas uma vez um parente (um filho) "falar mal" do seu morto (pai), e ainda na frente de outros membros da família. A crítica ou a descrição mais "severa" do morto faz parte, normalmente, do domínio dos vizinhos. 
Não deixa de ser impressionante, entretanto, que é sempre o "lado" negativo do esquecimento que é, sobretudo, percebido quando o amor está em jogo.

"Olhe, essa menina, vai piorando mais, sabe? Porque a gente diz que esquece, mas só se não gostar da pessoa, não é? Porque às vezes tem gente que é feito... sei lá! É feito uma cobra, não é? [...] Eu, quanto mais dias passam, mais eu vou me lembrando de papai, não é?" [S. Joel, 64 anos].

"Um ente querido não é esquecido, não é? Se ele for um querido morto ele não é esquecido. Ele só vai ser esquecido se ele não for querido [risos]" [Ivone, 47 anos].

Disso se segue que o esquecimento é prova de não-amor, enquanto que a lembrança, a memória, é precisamente a sua declaração, a proclamação de sua autenticidade. Aquele que ama não esquece nunca, menos ainda se se trata de um ente querido. Entretanto, o paradoxo do esquecimento se exprime ainda pelo fato de que o esquecimento dos maus momentos é condição quase necessária para a perpetuação (reprodução) desse amor, que tem no estabelecimento do terceiro tipo de memória, a memória-saudade, a sua condição. Antes de discuti-la, contudo, seria importante pensar sobre a própria categoria "saudade".

\section{QUANDO É QUESTÃO DE SAUDADE}

Saudade é, como se sabe, uma palavra portuguesa que exprime um sentimento de perda, de amor, de dor, mas também de prazer. A saudade é um elemento de orgulho de, entre outros, brasileiros e portugueses: é um termo que se diz só existir na língua portuguesa. ${ }^{12}$ Além disso, e no caso de Portugal, a saudade pode ser culturalmente construída como um elemento de identidade nacional, como discutido por Leal (2000), mesmo se essa relação entre saudade e identidade nacional em Portugal seja diferentemente sentida e mesmo reconhecida, tanto historicamente, quanto em termos de grupos sociais ou em casos de imigração (Leal 2000); em todo caso, a ideia de certa relação de particularidade entre saudade e lusofonia parece permanecer.

Assim, e ao que tudo indica, se o conjunto de sentimentos que a saudade engloba é universal, dito de outra forma, encontrado nas mais diversas culturas, por outro lado é difícil de encontrar sua substantivação, pois, no português, a saudade é substantivo, coisa, nome. Nesse sentido, a saudade é uma dessas

12 Já desde o início do século XX em Portugal e depois no Brasil tem havido um intenso debate sobre a exclusividade ou não da língua portuguesa sobre o conceito de saudade, havendo assim os "universalistas" e os "particularistas". A esse respeito, ver os comentários de DaMatta (1994), Leal (2000), e Nascimento e Menandro (2005). 
palavras que "apesar de um termo chave, não é fácil de traduzir, sendo aí onde repousa todo o problema da interpretação cultural" (Scheper-Hughes 1992: 435), como é o caso dos termos hau e mana. Isto porque, segundo DaMatta, a saudade é mais do que uma palavra, tendo em vista a densidade que possui: a saudade seria então "uma categoria básica de nossa existência" (DaMatta 1994: 18) brasileira. Trata-se, dessa forma, de uma

“... categoria do pensamento e da ação na acepção maussiana do termo, e [...] uma palavra com capacidade performativa, no sentido de John Austin. Uma categoria que - tal como ocorre com palavras de ordem [...] - ao ser dita e invocada, promove e implica um fazer, um empenho, uma perspectiva ou um compromisso, definindo um estado interno e permitindo ou desculpando uma ação externa" (DaMatta 1994: 19).

Pode-se ainda acrescentar as palavras de Scheper-Hughes, quando afirma que

“... os brasileiros concebem a saudade como a pura expressão da alma brasileira, de sua alta sensibilidade e da consciência do ambiente natural e social onde eles vivem, da sua forte percepção em relação à condição humana e as suas tragédias, e da perda, do desejo e, particularmente, da própria memória" (1992: 436).

É possível perceber, então, até que ponto esse vocábulo é cheio de sentidos. Mas, se se trata de um conceito-chave, isto se deve a que a saudade é onipresente, ou, como diz Soares:

"No Brasil, o termo saudade é constantemente empregado na palavra cotidiana e nas canções populares. Nos jornais, as telenovelas, poesia e literatura, nas portas dos cemitérios, pode-se comumente ler jardim das saudades. [...] Em suma, o termo se encontra em todo o país e os brasileiros são generosos no uso. Eles parecem nunca se cansar de sua utilização" (2001: 260).

É por estas razões que me junto a DaMatta para avançar que

“... temos na saudade uma categoria do espírito humano e, dentro dele, da manifestação de certa estrutura de valores ou ideologia. No caso, da ideologia luso-brasileira. Nesse sentido, a saudade é um conceito duplo. De um lado ela trata de uma experiência universal, comum a todos os homens em todas as sociedades: a experiência da passagem, da duração, da demarcação e da consciência reflexiva do tempo. De outro, porém, ela singulariza, especifica e aprofunda essa experiência, associando-a a elementos que não 
estariam presentes em outras modalidades culturais de medir, falar, sentir, classificar e controlar o tempo" (1994: 22).

Dessa forma, a saudade se refere ao tempo, trata-se de uma maneira cultural de elaborar relações com a duração, cujo conteúdo, acrescento, é composto pela afetividade e pela memória. É assim que a "saudade fala do tempo por dentro" (DaMatta 1994: 22), e por isso mesmo diria eu que ela seria muito mais uma categoria do "coração" do que do "pensamento". Isto porque penso que a reflexão de DaMatta, ao circunscrever a saudade na sua acepção de uma categoria do pensamento, remete a um excesso de intelectualismo, o que leva a diminuir ou esterilizar na reflexão antropológica a capacidade organizadora ou estruturante de um determinado sentimento. Assim, ao considerar a saudade como uma categoria do coração, procuro conjugar uma análise intelectualista a uma abordagem maussiana dos sentimentos, em que se compreendem estes últimos como intrínsecos às condições sociais, psíquicas e corporais dos sujeitos, e que têm seus desdobramentos no discutido por Leavitt (1996), como visto.

Do ponto de vista nativo brasileiro, portanto, pode-se avançar que a saudade conjugaria então a memória, o amor, o dom e o desejo de alguém ou de alguma coisa. É este conjunto que evocam meus informantes quando eles dizem sentir saudades de um ente querido:

“Os choros que a gente tem, a tristeza, é a separação, é a saudade! [...] Essas lágrimas são a saudade, porque a saudade é enorme quando um ente querido partiu" [D. Lucinda, 65 anos].

"Eu fico pensando ainda com saudade... Principalmente daqueles que a gente estima e gosta, não é?" [S. Durval, 61 anos].

Amor e afeição são, dessa forma, palavras de ordem da saudade. É com relação a um ser amado - ou a uma coisa amada - que se tem esse sentimento, ele é, ainda, pena, separação, lágrimas. Talvez por isso se diga no Brasil que "fulano partiu sem deixar saudades", para sinalizar que esse fulano não é amado, não é alguém de bem e que sua ausência não produz um vazio - a saudade é também o vazio deixado pela morte de um ente querido.

Poderia sugerir, a partir disso, que quando se trata de uma morte, a saudade preenche, ao mesmo tempo em que ela é esse vazio.

"O tempo alivia essa saudade, aí fica mais ou menos normal" [D. Hilda, 59 anos].

“Ah, a gente sente uma saudade, não é? É um vazio imenso. A gente perde uma pessoa e fica o vazio dessa pessoa. Até um certo tempo. Depois, 
a gente se acostuma, se acostuma [...]. A gente sente muito a falta do ente querido e depois a gente se acostuma [...]. A gente só fica com a saudade" [D. Hélia, 63 anos].

A morte deixa o vazio, a saudade alivia e aumenta o vazio. Depois do primeiro choque, segue o período do luto, e é durante esta etapa que se aprende a viver com este vazio, a transformá-lo em saudade, e ainda a viver com ela. Pode-se dizer que isto é realizar o trabalho do luto. É nesse sentido que o tempo é condição fundamental, e que a saudade é relação ao tempo, sendo também, seguindo DaMatta, concepção e controle do tempo. Além disso, a saudade é medida do tempo, assim como este último é o seu mestre; tendo em vista que o tempo pode tornar esta saudade menos dolorosa, mais aceitável, ele pode assim domesticá-la.

De qualquer forma, a saudade é um sentimento “doce-amargo"(Scheper-Hughes 1992), fonte de sofrimento e de prazer - de onde se deriva a expressão usada pelos brasileiros de "sentir saudade da saudade" -, mesmo se, no que concerne a saudade sentida pela perda de uma pessoa amada, parece ser mais difícil sentir um grande prazer, mesmo que amargo. De todo modo, uma boa parte do "prazer" fornecido pela saudade vem do fato de se poder matá-la. É dessa forma que as pessoas afirmam ir aos cemitérios em dia de Finados para matar a saudade de um parente morto. Todavia, o caráter mais doloroso deste tipo de saudade é a sua impossibilidade de ser completamente "morta".

"Hoje só me recordo dele [seu pai], não é? Sinto falta, me lembro com saudade. [...] Assim, todo dia me lembro dele. Porque normalmente eu costumo rezar antes de dormir, por isso que eu digo que todo dia eu me lembro, então normalmente, desde que ele morreu, eu rezo. E continuo. [...] Acho que a gente sente saudade e a gente vai sentir sempre" [Yolanda, 42 anos].

Consequentemente, a saudade é uma categoria consubstancial à memória (Reesink 2003; Nascimento e Menandro 2005). Da mesma maneira que esta última é intrínseca ao estado do luto. Por isso, é possível afirmar que o luto não é jamais completamente realizado, porque a memória e a saudade são permanentes. Um ente querido é insubstituível. Se ele é substituível, segundo meus informantes, é porque ele não era verdadeiramente querido.

Observa-se aqui que, à diferença do que acontece em situações de migração, como descritas por Soares (2002), em que a saudade é mais do que tudo um sentimento ou lógica da expectativa, da margem, da transição ou transitoriedade espacial, da possibilidade real de matá-la, como diriam meus informantes, a saudade em relação aos entes queridos expressa mesmo a impossibilidade 
dessa expectativa, ${ }^{13}$ assim como fala de uma fixação espacial nos túmulos, nos objetos e nos espaços circulados pelo ente querido. Há, portanto, diferença em relação à saudade-exílio e à saudade-morte, tendo em vista que, nesse último caso, mesmo se se pode falar da saudade que transforma a "ausência em presença" (Soares 2002), isso se realiza por um processo contrário em que há um movimento de materialização e fixação do morto através de marcos temporais e espaciais, que são prioritariamente orientados pela afetividade, pelo amor. ${ }^{14}$

Assim, diante do até agora exposto, pode-se dizer que a saudade alimenta e é alimentada pelo amor, pela afeição: quanto mais se ama, mais se sente saudade de alguém. E essas relações entre saudade e amor são estabelecidas através da memória, e em relação a espacialidades e temporalidades, produzindo entes queridos.

\section{TEMPO, ESPAÇO, MEMÓRIA, SAUDADE}

Estas interconexões e, talvez, circularidades descritas acima só podem ser pensadas analiticamente se tomarmos como condição primeira a morte de um ente querido ${ }^{15}$ como um evento, este pensado aqui como uma "diferença que faz diferença" e como "atos que modificam a ordem das coisas" (Sahlins 2007: 326-327). A morte de um ente querido se inscreve, sabe-se (Reesink 2003), em uma temporalidade, tanto coletiva quanto individual. Esta morte é assim ainda mais um evento, tendo em vista que rompe o tempo cotidiano, instaurando um tempo extracotidiano (Turner 1974). Voltando à vida ordinária, o indivíduo é transformado, pois "o evento abre em direção a uma situação nova, palheta inédita de possibilidades até aqui latentes ou impensadas" (Bensa 1997: 13), possibilitando a instauração do terceiro tipo de memória, a memória-saudade.

É interessante observar que essa discussão se aproxima da preocupação de Halbwachs (1997 [1950]) entre memória coletiva e memória individual, tempo e espaço. Assim, procurando escapar tanto a um psicologismo quanto a um hipersociologismo, parece-me que Halbwachs está em busca exatamente desses pontos de síntese e de interceção, desses encontros que possibilitam a realização da memória: são pontos de fusão entre (o ponto de vista do) indivíduo e coletividade, entre a duração (o vivido) e o tempo (universal, abstrato).

13 Ao menos não nessa vida. Para aqueles que acreditam no reencontro pós-morte - o que não é o caso para todos os católicos de Casa Amarela (Reesink 2003), há de fato um conteúdo de expectativa, mas que não tem o mesmo significado da expectativa nesse mundo.

14 Poder-se-ia acrescentar aqui a dimensão olfativa da memória. Seguindo o discutido por Stallybrass (2008), particularmente, as roupas que pertenceram ao morto guardam entranhados nos tecidos os seus cheiros (mas também as formas do seu corpo), materializando assim o morto na vida dos vivos, e ativando o potencial "doce-amargo" da saudade.

15 Tomo aqui, no caso específico, esse termo no seu sentido estrito e também no sentido metafórico em relação a toda e qualquer pessoa que tenha valor social do ponto de vista da coletividade. 
Nesse sentido, poder-se-ia ousar dizer que, para Halbwachs, quanto maior a profundidade temporal, maior a abstração descontínua da duração, que se transformaria em mito - e aqui em um sentido lévi-straussiano. E nesse processo, é exatamente a dimensão espacial que torna possível a cristalização e a estabilidade da memória, pois as imagens fabricadas no processo de memorizar são espacializadas, porque, segundo ele,

“... é só a imagem do espaço que, em razão da sua estabilidade, nos dá a ilusão de nunca mudar através do tempo e de reencontrar o passado no presente; mas é assim que também podemos definir a memória; e que apenas o espaço é suficientemente estável para poder durar sem envelhecer e sem perder nenhuma de suas partes" (Halbwachs 1997 [1950]: 236).

É interessante notar ainda a concordância que se pode encontrar entre esta afirmação de Halbwachs sobre o passado no presente e a reflexão de Soares de que a saudade nas sociedades lusófonas ${ }^{16}$ realiza o ato contraditório, e mesmo liminar e circular, de transformar a ausência em presença (Soares 2002). Essa discussão também se aproxima da ideia elaborada por Pascoaes, como apresentada por Leal (2000). Assim,

"Pascoaes de fato vê a saudade como algo que define a peculiaridade da psicologia étnica portuguesa em termos de sentimentos. Baseado em Duarte Nunes de Leão e Almeida Garret, Pascoaes definiu saudade como 'o desejo do ser ou da coisa amada junto com a dor da sua ausência. Desejo e dor da perda fundidos em um único sentimento' (Pascoaes 1986 [1912]: 25), o que combina um elemento carnal ou material - desejo - com um espiritual - dor da perda -, e uma orientação em direção ao passado - dor da perda e lembrança - com uma orientação em direção ao futuro - desejo e esperança. Assim, a saudade era vista por Pascoaes como um especial e contraditório sentimento relacionando universos que eram normalmente vistos como desconectados - o material e o espiritual, o passado e o presente" (2000: 274). ${ }^{17}$

Neste sentido, a partir da perspectiva aqui adotada, pode-se avançar que é no cruzamento (ou fusão) do tempo e do espaço, do indivíduo e da coletividade (e porque não dizer: do desejo, da perda, do espiritual, do material, da ausência na presença?) que a memória se desenvolve, ao realizar uma síntese

16 Soares (2002) realizou pesquisa em três países - Cabo Verde, Portugal e Brasil -, fazendo uma relação entre saudade, migração, lógicas culturais e relações interétnicas.

17 Parece que certo caráter contraditório ou paradoxal da saudade, apontado por Pascoaes no início do século XX, permanece como um dos pontos recorrentes nas discussões atuais sobre a saudade, por exemplo, Soares (2002). 
simbólica (Sahlins 2007), acrescentando que, do ponto de vista do campo etnográfico aqui discutido, isto só é possível porque esse processo simbólico é intrinsecamente carregado de afetividade.

É razoável avançar, então, que a morte de um ente querido traz para a temporalidade um antes e um depois.

"Nunca vai ficar a mesma coisa. [...] Porque quando a pessoa é querida eu acredito que não tem [isso de] melhorar ou piorar, não. Eu acredito que a gente vai só amadurecendo p'ra gente conviver com aquilo, não é? A gente vai amadurecendo com um tempo. É [como] um corte, ele vai, sara, mas a cicatriz está sempre lá" [André, 23 anos].

"Eu creio que o povo lá de fora esquece muito mais rápido [que a família]. Para eles, não foi ninguém da família, eles estão calmos. Mas a gente que está dentro da família, que está passando por aquilo, a gente sofre muito e p'ra esquecer vai demorar um bom tempo [...]. O povo da rua se recupera rápido, não é? Eles ficam só pensando na família: 'pôxa, como é que fulana está se recuperando?' As pessoas da família é mais difícil, sofre muito e sempre está relembrando, acho que sempre que chega aquela data vai ficar uma data marcada" [Ana, 21 anos].

A morte de um ente querido deixa gravado na duração marcos que se tornam pontos de referência, em relação aos quais os vivos se situam e constroem suas narrativas pessoais, marcos estes que se atualizam no contexto da performance ritual. No tempo cortado em dois pelo evento da morte, o antes se torna um momento longínquo (por exemplo, o "quando meu pai era vivo" das narrativas), ou próximo (as situações que precedem e/ou que terminam na morte). Acontece o mesmo para o depois: próximo por ocasião dos rituais, do luto (memória-perda, memória-sofrimento), e longínquo (o presente e a memória-saudade). Isto pode ser esboçado como segue:

Morte
Longínquo Antes próximo $\quad$ Depois próximo $\longrightarrow$ Luto

É durante o depois próximo que os sobreviventes vivem e realizam as exéquias. É nesse momento que o trabalho do luto é iniciado, encaminhando-se em direção ao depois longínquo; e é justamente então que os pontos de memória são presos para sempre na vida dos sobreviventes. Mas é também nesse depois longínquo que um dos rituais mais importantes da lógica católica é anualmente 
realizado e que, no Brasil, é significativamente chamado do dia da saudade (Reesink 2010). ${ }^{18}$ Não deixa de ser curioso observar que a saudade dos mortos é comemorada, ${ }^{19}$ ao mesmo tempo em que os mortos são comemorados.

A memória-saudade é, então, estabelecida na duração do depois longínquo. É sobretudo, ao longo desse período que os objetos (Déchaux 1997; Baudry 1999), as imagens (Déchaux 1997), os fatos e os acontecimentos vividos conjuntamente são mais do que nunca "lugares de memória", são mais do que nunca imagens-espaços.

"Eu acho que eu senti mais a morte dele [do amigo]... Acho que se um irmão meu morresse eu não sentia tanto [...]. Até hoje eu não paro de me lembrar dele, sabe? Principalmente quando eu estou dirigindo... Porque ele foi quem me ensinou, sabe?" [Josué, 27 anos].

"O ser humano, ele grava todas as situações ao longo de toda a sua vida, então seja qual for... Se eu vejo uma foto, então aquele momento está ligado a uma série de emoções que nos [toca] na vida da gente, seja em casa dando um abraço, mostrando, nos ensinando alguma coisa. Então, o ser humano, ele é ligado muito aos sentidos. Então é uma coisa que sempre faz a gente lembrar e mexer com a emoção da gente de alguma forma. Como eu disse: faz parte dum ciclo de vida, então a gente acaba entendendo [isso]" [Marcos, 24 anos].

Marcos diz claramente: os objetos, os momentos são marcos de memória. Eles despertam toda uma gama de lembranças carregadas de emoção, porque cheios de amor e, mais amplamente, de saudade. Aqui, dessa forma, observa-se que tanto o tempo quanto os espaços percebidos e relacionados ao ente querido adquirem valor (ou seja, são marcos de memória), pois são carregados de afetividade: o valor simbólico adquirido por estes elementos só acontece porque o seu conteúdo é prioritariamente afetivo.

\section{POR FIM}

A produção do ente querido surge como categoria de pessoa fundamental da cosmologia católica no contexto etnográfico aqui discutido, particularmente no que se refere às ligações entre vivos e mortos. Sua produção, contudo, está

18 Não deixa de ser interessante notar que, atualmente, particularmente nos cemitérios privados, há uma tendência a esvaziar o conteúdo religioso identitário do dia (não é mais um dia puramente católico, como é ainda hoje concebido pelos brasileiros) para marcá-lo como dia de rememorar os mortos, sublinhando mais fortemente o dia como aquele da saudade dos mortos. Ver Morais (2009).

19 Em relação a outro contexto etnográfico, C. Eckert (1997) já discutiu sobre esta questão da "comemoração da saudade". 
condicionada ao que se pode considerar como um complexo cognitivo/afetivo, em que os diferentes tipos/tempos de memória, afetos (particularmente a saudade como categoria do coração) e rituais estão em processos de interconexão com o tempo e o espaço, ao mesmo tempo em que só é possível produzir um ente querido quando do evento de morte e a partir das relações de parentesco ou de afinidades eletivas entre vivos, e entre vivos e mortos.

No princípio da reflexão sobre essa produção dos entes queridos afirmei que os vivos vivem dois tipos de memória, a memória-perda e a memória-sofrimento, tomando-as como categorias nativas com potencial analítico. A primeira é aquela que é vivida entre o momento da morte e uma parte do depois próximo; a segunda, aquela que se instaura durante o depois próximo. Em um segundo momento introduzi um terceiro tipo de memória, que chamo de memória-saudade, associando-a ao depois longínquo. Com essa separação esquemática quero dizer que a saudade não está presente nos outros tipos de memória? Ao contrário. De fato, como visto, saudade e memória se conjugam, uma sendo intrínseca à outra. Nesse sentido, evocar a memória dos mortos significa dizer que aí se encontra a saudade, do mesmo modo que falar de saudade implica necessariamente a memória. Disso segue que, em todo tipo de memória ligado às relações entre vivos e mortos, a saudade está presente. $\mathrm{O}$ fato de classificar como saudade uma dessas memórias não nega o que acabo de dizer. A questão é que, no processo de cada uma dessas memórias, há um aspecto/categoria diferente que é evidenciada ou sublinhada - a perda, o sofrimento ou a saudade, apesar de esses três aspectos/categorias comporem cada tipo de memória, e, por conseguinte, estarem presentes nas lembranças que permanecem.

Mas essas lembranças são também acompanhadas de um reconforto: os mortos fazem parte da vida, porque não são simplesmente mortos, mas entes queridos, pois estão implicados em relações de parentesco ou de afinidades eletivas. Enquanto tais, eles constroem ainda a história, desde que suas ligações de afetividade com os vivos permaneçam. Estas ligações/relações são continuadas, (re)produzidas e reafirmadas, de maneira inter-relacionada, pela memória, pela saudade e pela elaboração e realização do complexo ritual fúnebre católico - com suas implicações afetivas e de obrigações na ajuda à salvação completa das almas: o todo é possibilidade porque realiza potencialmente essa síntese simbólica entre espaço e tempo, nos sujeitos e através deles.

A perpetuação da história dos mortos é, nesse sentido, possível porque os vivos estabelecem suas próprias narrativas por via destas relações e, enquanto um vivo alimente ainda essas relações, o morto continua fazendo história. É assim que um morto é produzido como ente querido, graças à memória, a saudade e a vida dos vivos. É ainda por esta razão que o trabalho do luto não se completa jamais, enquanto existir memória e saudade, pois o morto, o ente querido, conserva seu lugar no coração dos vivos. 


\section{BIBLIOGRAFIA}

AUGÉ, Marc, 1998, Les formes de l'oubli. Paris, Payot/Rivages.

BAUDRY, Patrick, 1999, La place des morts: Enjeux et rites. Paris, Armand Colin.

BENSA, Albert, 1997, "Images et usages du temps", Terrain, 29: 5-18.

BLOCH, Maurice, e Jonathan PARRY, 1982, Death and the Regeneration of Life. Cambridge/ Londres/Nova Iorque, Cambridge University Press.

CAMPOS, Roberta, 2002, "Sofrimento, misericórdia e caridade em Juazeiro do Norte: uma visão antropológica das emoções na construção da sociabilidade", Ciência \& Trópico, 30 (2): 253-266.

COSTA, Lívia, 2002, Qu'est-ce qui fait crier les crentes? Émotion, corps et délivrance à l'Église Universelle du Royaume de Dieu (Bahia-Brésil). Paris, École des Hautes Études en Sciences Sociales, tese de doutorado.

D'AGOSTINO, Federico, 1977, Images of Death and Symbolic Construction of Reality in a Southern Italian Town. Los Angeles, The Red Hill Press.

DaMATTA, Roberto, 1994, "Antropologia da saudade", em Roberto DaMatta, Conta de Mentiroso: Sete Ensaios de Antropologia Brasileira. Rio de Janeiro, Rocco, 17-35.

DANFORTH, Loring M., 1982, The Death Ritual of Rural Greece. Princeton, Princeton University Press.

DÉCHAUX, Jean-Hugues, 1997, Le souvenir des morts: Essai sur le lien de filiation. Paris, PUF.

ECKERT, Cornelia, 1997, "A saudade em festa e a ética da lembrança", Estudos Feministas, 5 (2): 182-192.

HALBWACHS, Maurice, 1994 [1925], Les cadres sociaux de la mémoire. Paris, Albin Michel.

__, 1997 [1950], La mémoire collective. Paris, Albin Michel.

KLEINMAN, Arthur, Veena DAS, e Margaret LOCK, 1997, Social Suffering. Berkeley, University of California Press.

LEAL, João, 2000, “The making of saudade”, em Ton Dekker, John Helsloot e Carla Wijers (orgs.), Roots and Rituals: The Construction of Ethnic Identities. Amesterdão, Het Spinhuis, 267-288.

LEAVITT, John, 1996, "Meaning and feeling in the anthropology of emotions", American Ethnologist, 23 (3): 514-539.

LINS, Daniel S., 2001, "Esquecer não é crime”, em Daniel Lins, S. Costa e A. Vereis (orgs.), Nietzsche e Deleuze: Identidade e Paixão. Rio de Janeiro, Relume Dumará, 45-62.

METCALF, Peter, e Richard HUNTINGTON, 1991, Celebrations of Death: The Anthropology of Mortuary Ritual. Cambridge, Cambridge University Press.

MORAIS, Isabela, 2009, Pela Hora da Morte: Estudo sobre o Empresariar da Morte e do Morrer, Uma Etnografia no Grupo Parque das Flores, em Alagoas. Recife, Universidade Federal de Pernambuco, tese de doutorado.

NASCIMENTO, Adriano, e Paulo MENANDRO, 2005, "Memória social e saudade: especificidades e possibilidades de articulação na análise psicossocial de recordações", Memorandum, 8: 5-19.

PASCOAES, Teixeira de, (1912 [1986]), "O espírito lusitano ou o saudosismo", em A. Botelho e A. B. Teixeira (orgs.), Filosofia da Saudade. Lisboa, IN-CN, 2 1-35.

POLLAK, Michel, 1993, Une identité blessée: Études de sociologie et d'histoire. Paris, Metailié. 
REESINK, Mísia, 2003, Les passages obligatoires: Cosmologie catholique et mort dans le quartier de Casa Amarela, à Recife (Pernambuco-Brésil). Paris, École des Hautes Études en Sciences Sociales, tese de doutorado.

REESINK, Mísia, 2010, "Reflexividade nativa: quando a crença dialoga com a dúvida no período de finados”, Mana, 16 (1): 151-177.

ROSALDO, Renato, 1993, Culture and Truth: The Remaking of Social Analysis. Londres, Routledge.

SAHLINS, Marshal, 2007, Cultura na Prática. Rio de Janeiro, Editora UFRJ.

SARTI, Cynthia, 2001, "A dor, o indivíduo e a cultura", Saúde e Sociedade, 10 (1): 3-13.

SCHEPER-HUGHES, Nancy, 1992, Death without Weeping: The Violence of Everyday Life in Brasil. Berkeley e Los Angeles, University of California Press.

SOARES, Martin, 2001, “Des émotions métissées: hétéronymie et dynamique de l'altérité dans la saudade luso-afro-brasileira”, em Jean-Baptiste Martin (org.), Usages sociaux de la mémoire et de l'imaginaire au Brésil et en France. Lyon, Presses Universitaires de Lyon, 259-270.

— 2002, "Dynamique, résistance et transgression émotionelles de la saudade: anthropogie d'un sentiment métis (Portugal - Brésil - Cap-Vert)", Parcours Anthropologiques, 2: 45-60 (disponível em < http://recherche.univ-lyon2.fr/crea/IMG/pdf/PARCOURS_ANTHROPOLOGIQUE2002.pdf $>$ (acesso em 6-10-2010).

STAllybrass, Peter, 2008, O Casaco de Marx: Roupas, Memória, Dor. Belo Horizonte, Autêntica.

THOMAS, Louis-Vincent, 1975, Anthropologie de la mort. Paris, Payot.

—, 1985, Rites de mort: Pour la paix des vivants. Paris, Fayard.

TOREN, Christina, 2006, "Como sabemos que é verdade? O caso do mana em Fiji", Mana, 12 (2): 449-477.

TURNER, Victor, 1974, O Processo Ritual, Rio de Janeiro, Vozes.

VAN GENNEP, Arnold, 1969 [1909], Les rites de passage: Études systématiques des rites. Paris, Mouton \& Co. e Maison des Sciences de l'Homme. 